CASE REPORT

\title{
Pantoea species-A Rare Cause of Central Venous Catheter Related Sepsis in Hemodialysis Patient
}

\author{
Mital D. Parikh, Maulin K. Shah \\ Shree Krishna Hospital, H. M. Patel Institute of Medical Care and Education, Karamsad, Gujarat, India
}

\begin{abstract}
There has been a significant increase in nosocomial infections in Intensive Care Units and Oncology Department. Sepsis is a major cause of morbidity and mortality in chronic kidney disease patients. In hemodialysis patient, central venous catheter related blood stream infections are major cause for concern. Most common organisms isolated are gram positive which usually respond to antibiotics and sometimes needing catheter removal. However Pantoea species have been rarely reported as causative agent of CVC sepsis. Herein we report a case of Pantoea species causing CVC sepsis in hemodialysis patient. J Microbiol Infect Dis 2020; 10(2):103-105.
\end{abstract}

Keywords: Pantoea, Central venous catheter, Hemodialysis

\section{INTRODUCTION}

Hemodialysis patient are usually dependent on central venous catheter for dialysis and its infection is a major source of systemic sepsis in them. Gram positive organisms are most commonly isolated which usually respond to antibiotics rarely needing catheter removal. Pantoea agglomerans is member of Enterobacteriaceae that inhabits plants, soil and water [1].

Septic arthritis \& synovitis are the most common infection caused by $P$. agglomerans [2], but Pantoea also causes epidemic of septicaemia due to contaminated intravenous products. Cotton pledgets are continuously used by nurses and physicians in hospital which may be contaminated in many ways and $P$. agglomerans survives some steps of the autoclaving process [3]. However, $P$. agglomerans is not a frequent cause of endogenous nosocomial infections.

\section{CASE REPORT}

A 61 year old male patient was admitted in emergency department on $17^{\text {th }}$ September 2019 with complaints of fever, medium grade with chills since two days and decreased oral intake with decreased alertness \& hypotension (80 $\mathrm{mmHg}$ systolic). He was a known case of diabetes mellitus and hypertension with chronic kidney disease stage 5 . He was initiated on hemodialysis on $27^{\text {th }}$ August 2019 via right internal jugular central venous catheter and was continued on same catheter for hemodialysis, twice a week. In view of suspected catheter related blood stream infection, blood samples drawn from a peripheral vein as well as both lumens of catheter \& sent for culture in aerobic and anaerobic blood culture bottles (BacT/Alert FA; BioMerieux, Mercy l'Etoile, France). The catheter was removed with new left internal jugular catheter inserted. He was started on injectable antibiotics- ceftazidime. Ionotropes were started (Injectable Noradrenaline-adjusted as per blood pressure). He was continued on slow low efficiency dialysis alternate day.

After a period of 1-3 days of incubation (incubator BacT/Alert/3D; BioMerieux, Mercy l'Etoile, France), aliquots of broth were routinely subcultured into $5 \%$ sheep blood agar and McConkey agar. Identification as pantoe sp. was carried out by Vitek system (bioMérieux, Marcyl'Etoile, France). On blood agar plates yellow, pinpoint-sized and smooth-surface colonies were observed. The peripheral vein sample also showed same results, therefore a contamination of blood by the catheter should be considered.

Correspondence: Dr. Mital D. Parikh, Shree Krishna Hospital, H. M. Patel Institiute of Medical Care and Education, Karamsad, Gujarat, India 
All isolates were consistently sensitive to cefepime, cefoperazone- sulbactum, ceftazidime, quinolones, gentamicin, doripenem, amikacin, gentamicin, cotrimoxazole while they were resistant/intermediate to amoxycillinclavulanate and cefuroxime. His total counts showed a decreasing trend (Table1). His blood pressures improved and requirement of inotropes stopped over a span of 5 days. He was discharged in hemodynamically stable state and was on regular follow up for hemodialysis alternate days. His IV antibiotics were continued for total of 14 days. He remained asymptomatic, blood pressures were stable. His repeat blood cultures (sent after one week of completion of antibiotics) turned out to be negative.

Table 1. Laboratory values of our patient.

\begin{tabular}{lcccc}
\hline Variable & 18.9 .19 & 20.9 .19 & 22.9 .19 & 10.10 .19 \\
\hline $\begin{array}{l}\text { Hemoglobin } \\
(\mathrm{g} / \mathrm{dl})\end{array}$ & 11.4 & 10.3 & 9.7 & 8.7 \\
$\mathrm{WBC} / \mathrm{mm}^{3}$ & 28,700 & 16,600 & 14,100 & 11,600 \\
$\begin{array}{l}\text { Platelet count } \\
/ \mathrm{mm}^{3}\end{array}$ & 227,000 & 165,000 & 235,000 & 412,000 \\
\hline
\end{tabular}

\section{DISCUSSION}

From our results we conclude that Proteus sp. is able to cause CVC sepsis, however the source of these Pantoea infections remains to be investigated.

Cancer chemotherapy or central venous catheterization can be predisposing factors to cases of bacteremia due to unusual organisms [1] including Listeria, Salmonella and Campylobacter. Most of the cancer and hemodialysis patients including chronic kidney disease are immunocompromised; clinical signs in them are often subtle and misleading, sometime making it difficult to identify the source of the infection [2]. Pantoea agglomerans is member of Enterobacteriaceae that inhabits plants, soil, water; they have been reported as both commensal and pathogen of animals and humans [3]. Septic arthritis \& synovitis are the most common infection caused by $P$. agglomerans [4], but Pantoea has been also involved in nationwide epidemic of septicaemia due to contaminated intravenous products [5], an outbreak secondary to contaminated parental nutrition [6], osteitis [7], colelithiasis [8], occupational respiratory infections and skin allergy [9], blood stream infection in an elderly person [10] and peritonitis [11].

Pantoea $s p$ are clearly opportunistic pathogens rarely causing disease in otherwise healthy individuals [12]. It grows well at $4{ }^{\circ} \mathrm{C}$, is often associated with plants, and can be readily recovered from cotton $[13,14]$. Infections by $P$. agglomerans are usually associated with an identifiable exogenous source]. Therefore Pantoea sp. are often associated with outbreaks due to contaminated intravenous solutions and stored blood products as well as "cotton fever" in intravenous drug abusers $[13,15]$. Pantoea spp. have been reportedly found in samples obtained from cotton swabs, intra-arterial devices, as well as plants and plant materials [12]. Cotton pledgets are continuously used by nurses and physicians in hospital which may be contaminated in many ways. $P$. agglomerans has been reported to survive some steps of the autoclaving process [5]. However $P$. agglomerans, which is ubiquitous in nature, is not a frequent cause of endogenous nosocomial infections. Intrinsic $P$. agglomerans susceptibility to beta-lactam antibiotics [12], might account for the limited number of reports on Pantoea outbreaks.

\section{ACKNOWLEDGMENTS}

Declaration of Conflicting Interests: The authors declare that they have no conflict of interest.

Financial Disclosure: No financial support was received.

\section{REFERENCES}

1. Gavini F, Mergaert J, Beji A, et al. Transfer of Enterobacter agglomerans (Beijerinck 1888) Ewing and Fife 1972 to Pantoea gen. nov. as Pantoea agglomerans comb. nov. and description of Pantoea dispersa sp. nov. Int J Syst Bacteriol 1989; 39: 337-345.

2. Kratz A, Greenberg D, Barki Y, Cohen E, Lifshitz M. Pantoea agglomerans as a cause of septic arthritis after palm tree thorn injury; case report and literature review. Arch Dis Child 2003; 88(6):542-544. doi:10.1136/adc.88.6.542

3. Mackel DC, Maki DG, Anderson RL, Rhame FS, Bennett JV. Nationwide epidemic of septicemia caused by contaminated intravenous products: mechanisms of intrinsic contamination. J Clin Microbiol 1975;2(6):486-497 
4. Beebe JL, Koneman EW. Recovery of uncommon bacteria from blood: association with neoplastic disease. Clin Microbiol Rev 1995; 8(3):336-356.

5. Gullo A, Iscra F, Di Capua G, et al. Sepsis and organ dysfunction: an ongoing challenge. Minerva Anestesiol 2005;71(11):671-699.

6. Habsah H, Zeehaida M, Van Rostenberghe $\mathrm{H}$, et al. An outbreak of Pantoea spp. in a neonatal intensive care unit secondary to contaminated parenteral nutrition. The Journal of Hospital Infection 2005; 61(3): 213-218.

7. Laporte C, Demachy MC, Thevenin-Lemoine C. Tibial osteitis caused by Pantoea agglomerans after open grade IIIB tibial shaft fracture. Rev Chir. Orthop Reparatrice Appar Mot 2002; 88, 625-627.

8. 8.Flores C, Maguilnik I,Hadlich E, Goldani L.Z. Microbiology of choledochal bile in patients with choledocholithiasis admitted to a tertiary hospital. J Gastroenterol Hepatol 2003; 18, 333-336.

9. Milanowski J, Dutkiewicz J, Potoczna H, Kuś L, Urbanowicz B. Allergic alveolitis among agricultural workers in eastern Poland: a study of twenty cases. Ann Agric Environ Med. 1998; 5(1):31-43.

10. De Baere T, Verhelst R, Labit C, et al. Bacteremic infection with Pantoea ananatis. J Clin Microbiol 2004; 42(9):4393-4395

11. 11.Lim PS, Chen SL, Tsai CY, Pai MA. Pantoea peritonitis in a patient receiving chronic ambulatory peritoneal dialysis. Nephrology (Carlton) 2006; 11(2):97-99.

12. Sanders WE Jr, Sanders CC. Enterobacter spp.: pathogens poised to flourish at the turn of the century. Clin Microbiol Rev 1997; 10(2):220-241.

13. Ferguson R, Feeney C, Chirurgi VA. Enterobacter agglomerans--associated cotton fever. Arch Intern Med 1993; 153(20):2381-2382.

14. Lindh E, Kjaeldgaard P, Frederiksen W, Ursing J. Phenotypical properties of Enterobacter agglomerans (Pantoea agglomerans) from human, animal and plant sources. APMIS 1991; 99(4):347-352.

15. Matsaniotis NS, Syriopoulou VP, Theodoridou MC, Tzanetou KG, Mostrou GI. Enterobacter sepsis in infants and children due to contaminated intravenous fluids. Infection Control 1984; 5(10):471-477. 